\title{
Efficacy predictors of lung volume reduction with Zephyr valves in a European
} cohort

\author{
Felix J.F. Herth, Marc Noppen, Arschang Valipour, Sylvie Leroy, \\ Jean-Michel Vergnon, Joachim H. Ficker, Jim J. Egan, Stefano Gasparini, \\ Carlos Agusti, Debby Holmes-Higgin and Armin Ernst, on behalf of the International \\ VENT Study Group
}

ABSTRACT: The Endobronchial Valve for Emphysema Palliation Trial (VENT) was a multi-centre, prospective, randomised, controlled trial conducted to evaluate the safety and effectiveness of unilateral endobronchial valve (EBV) treatment. The purpose of this analysis was to assess outcomes in the previously unreported European VENT study cohort.

Patients with advanced emphysema were randomly assigned (2:1) to receive Zephyr® (Pulmonx Inc., Redwood City, CA, USA) EBV treatment $(n=111)$ or medical management $(n=60)$.

At 6 months, EBV patients demonstrated a significant improvement compared with the controls for mean \pm SD change in forced expiratory volume in $1 \mathrm{~s}(7 \pm 20 \%$ versus $0.5 \pm 19 \% ; p=0.067)$, cycle ergometry $(2 \pm 14$ W versus $-3 \pm 10 W ; p=0.04)$ and St George's Respiratory Questionnaire $(-5 \pm 14$ points versus $0.3 \pm 13$ points; $p=0.047$ ). At 12 months, the magnitude of the difference between groups for change from baseline was of similar magnitude to the differences seen at 6 months. Rates for complications did not differ significantly. EBV patients with computed tomography (CT) scans suggestive of complete fissure and lobar occlusion had a mean \pm sD lobar volume reduction of $-80 \pm 30 \%$ and $>50 \%$ met minimal clinical difference thresholds. The degree of emphysema heterogeneity did not preclude excellent outcomes.

Unilateral lobar volume reduction using EBV treatment is safe and superior clinical results correlated with CT suggestive of complete fissures and successful lobar occlusion. Emphysema heterogeneity was not critical for determining positive outcomes.

KEYWORDS: Bronchoscopy, collateral ventilation, emphysema, endobronchial valves, interlobar fissures

E mphysema is a debilitating and progressive disease which presents a major health problem around the world. Medical treatment is well established and widely used but is of limited efficacy [1,2]. Lung volume reduction surgery has been found to alleviate symptoms and improve survival rate in a subgroup of patients with heterogeneous emphysema [3-5] but the reported risks of procedure-related morbidity and mortality are substantial [6].

Endobronchial methods designed to perform lung volume reduction are being pursued as a less invasive means to achieve the benefits associated with surgical intervention [7-24]. The Endobronchial Valve for Emphysema Palliation

For editorial comments see page 1287.
AFFILIATIONS

Author affiliation details and a full list of the International VENT study investigators are presented in the Acknowledgements.

CORRESPONDENCE

F.J.F. Herth

Hospital Thoraxklinik,

University of Heidelberg

Member of the German Center for

Lung Research

Amalienstraße 5

D-69126 Heidelberg

Germany

E-mail: Felix.Herth@thoraxklinik-

heidelberg.de

Received:

Sept 162011

Accepted after revision:

Dec 102011

First published online:

Jan 262012 
higher level of clinical response with EBV therapy. Complete lobar fissures are indicative of absence of collateral ventilation. The purpose of this analysis was to evaluate clinical outcomes in the previously unreported European cohort of the VENT study. In addition, this independent data set was used to analyse the clinical effect of the factors found to be associated with outcomes in the USA study cohort.

\section{METHODS}

\section{Study design and participants}

Details of the trial design and study eligibility criteria for the VENT study have been reported previously [21, 25]. Selection criteria were adopted from the surgical candidacy criteria from the National Emphysema Treatment Trial (NETT) study [4]. Prior to undergoing screening to determine eligibility for study participation, all patients provided written informed consent as approved by the ethics committee overseeing each clinical site. All patients underwent 6-8 weeks of a full pulmonary rehabilitation programme. Patients who remained eligible for the study after undergoing the pulmonary rehabilitation programme $(n=171)$ were randomly assigned $2: 1$ to receive therapy using the Zephyr ${ }^{\circledR}$ EBV (Emphasys Medical, now Pulmonx Inc., Redwood City, CA, USA) (treatment group with 111 patients) or standard medical care (control group with 60 patients). Patients in both study groups were followed up at 1 , 3,6 and 12 months.

Clinical effectiveness measures included forced expiratory volume in $1 \mathrm{~s}$ (FEV1), the 6-min walk distance (6MWD) test, cycle ergometry workload and health-related quality of life assessed using the St George's Respiratory Questionnaire (SGRQ). Safety was evaluated by determining the rates of major complications, including death, empyema, haemoptysis, pneumonia distal to valves, pneumothorax, ventilator-dependent respiratory failure and chronic obstructive pulmonary disease (COPD) exacerbations. Multi-row detector high-resolution computed tomography (HRCT) was used to determine study eligibility and to evaluate 6-month follow-up mechanistic outcome measures. The HRCT images were read and analysed by a blinded core laboratory.

\section{Study treatments}

Medical therapy

Optimal medical therapy was defined as maximal medical treatment for stable COPD as presented in the 2001 National Institutes of Health (NIH)/World Health Organization (WHO) Global Initiative for Chronic Obstructive Lung Disease (GOLD) guidelines [26]. As recommended in the GOLD standards, all patients enrolled in the study received therapy that included: 1) education; 2) pharmacological treatment; and 3) nonpharmacological treatments. The education component consisted of smoking cessation support. Maintenance bronchodilator therapy included an inhaled long-acting $\beta$-agonist, an inhaled anticholinergic, or both, and was administered by metered dose inhaler, dry powder inhaler or drug aerosol. These treatments were initiated at randomisation, and for the patients randomised to the treatment arm, it was required that the medical treatment regime was stable for 1 month prior to the EBV procedure. All patients received oxygen therapy as necessary and were strongly encouraged to follow a maintenance pulmonary rehabilitation programme at home.

\section{EBV procedure}

A flexible bronchoscope with or without rigid bronchoscopy was used to perform valve placement. The procedural anaesthetic was selected and administered according to the standard local protocols followed for performing bronchoscopy. Antibiotics (second- or third-generation cephalosporin or fluoroquinolone) were given intravenously prior to and for $24 \mathrm{~h}$ after the procedure. Patients were provided with oral antibiotics for 7 days.

The EBV used in the study was the Zephyr ${ }^{\circledR}$ one-way, silicone duckbill valve mounted in a nickel-titanium self-expanding retainer covered with a silicone membrane. During the study, the valve was provided in two sizes to accommodate different airway diameters $(4.0-7.0 \mathrm{~mm}$ and $5.5-8.5 \mathrm{~mm})$. Valves were placed unilaterally in lobar, segmental, or subsegmental bronchi in the targeted lobe with the goal of complete occlusion. The treating physician also determined the number of valves to place. The EBV procedure has been previously described in detail $[21,25]$.

\section{Radiographic evaluation of CT scans}

HRCT images were utilised in the study to perform subject eligibility screening, treatment targeting, assessment of interlobar fissure integrity and lobar volume reduction, and examination of technical success achieved with EBV placement (lobar occlusion). Acquisition of images was standardised across clinical sites and radiographic evaluation of CT scans included blinded assessment of images by a core reading laboratory. The HRCT scans were collected at baseline and at 6 months. The HRCT images were analysed quantitatively using automated software and qualitatively depending on the variable of interest.

Study subject eligibility screening included review of radiological findings associated with emphysema distribution. Emphysema distribution was quantified by determining lobar destruction scores and calculating the difference between the target treatment lobe and the ipsilateral non-target lobe. Lobar destruction scores were generated using specialised software to calculate the proportion of image voxels within a lobe that fell below a pre-defined Hounsfield unit threshold (-910 HU) and reported as a density score (as a percentage) for each lung lobe. For example, a density score of $75 \%$ meant that $75 \%$ of the volume of that lobe met the Hounsfield threshold and was considered destroyed by emphysema. The lobe targeted for EBV treatment had the highest percentage of emphysema as determined by the core laboratory. Emphysema heterogeneity score was defined as the difference (in per cent) between the density scores of the target lobe and the ipsilateral non-target lobe.

CT images were also reviewed to calculate volumetric change in the target treatment lobe (atelectasis score). This was calculated using the formula: volume in target lobe at day 180 subtracted from volume in lobe at baseline, divided by volume in lobe at baseline. The resulting value indicates progressive volume loss up to a hypothetical complete atelectasis $(-100 \%$ or -1.00$)$. The target lobe atelectasis score is a measure of target lobe volume reduction (TLVR) over 6 months of study follow-up.

Additional HRCT measures which were collected to support post hoc analysis of factors related to treatment effect included determination of inter-lobar fissure integrity (baseline HRCT) 
and evaluation of valve placement in the targeted lumen (6month HRCT). Determination of both inter-lobar fissure integrity and valve placement was performed manually. A "complete" fissure was defined as having $>90 \%$ of the fissure present on thin-slice HRCT on at least one axis (sagittal, axial or coronal views). Lobar occlusion was defined as the visual identification of valves in all treated segmental airways being situated without evidence of leak. The latter was determined by identifying at least one valve in all segmental airways with the EBV cylinder within the airway and no evidence of air between the valve and the wall to suggest leak.

\section{Statistical methods}

The a priori sample size estimation for the VENT study was designed to provide study power of $90 \%$ to detect a mean improvement of $15 \%$ in the FEV1 and a mean improvement of $17 \%$ in distance on the $6 \mathrm{MWD}$ test for the EBV group

\begin{tabular}{|c|c|c|c|}
\hline Variable & EBV therapy & Control & p-value \\
\hline Patients n & 111 & 60 & \\
\hline \multicolumn{4}{|l|}{ Demographic characteristics } \\
\hline Age yrs & $59.7 \pm 7.9$ & $60.4 \pm 7.4$ & 0.576 \\
\hline Males & $75(68)$ & $48(80)$ & 0.084 \\
\hline White $^{\#}$ & $111(100)$ & $59(98)$ & \\
\hline $\mathrm{BMl} \mathrm{kg} \cdot \mathrm{m}^{-2}$ & $22.9 \pm 3.8$ & $23.8 \pm 3.8$ & 0.168 \\
\hline \multicolumn{4}{|l|}{ Smoking history } \\
\hline Ever smoked & 109 (98) & $60(100)$ & \\
\hline Yrs of smoking & $33.7 \pm 8.9$ & $34.3 \pm 8.1$ & 0.700 \\
\hline Pack-yrs & $76.9 \pm 6.1$ & $47.1 \pm 19.6$ & 0.413 \\
\hline Receiving oxygen therapy & $80(72)$ & $29(48)$ & 0.002 \\
\hline \multicolumn{4}{|l|}{ Arterial blood gas $\pi$} \\
\hline $\mathrm{Pa}, \mathrm{O}_{2} \mathrm{mmHg}$ & $69.3 \pm 10.6$ & $69.7 \pm 11.5$ & 0.814 \\
\hline $\mathrm{Pa}, \mathrm{CO}_{2} \mathrm{mmHg}$ & $38.9 \pm 4.6$ & $38.6 \pm 5.3$ & 0.691 \\
\hline \multicolumn{4}{|l|}{ Lung function } \\
\hline FEV 1 L & $0.91 \pm 0.29$ & $0.94 \pm 0.30$ & 0.529 \\
\hline FEV $1 \%$ pred & $29 \pm 8$ & $30 \pm 8$ & 0.451 \\
\hline FVC L & $2.50 \pm 0.73$ & $2.67 \pm 0.86$ & 0.158 \\
\hline FVC \% pred & $61 \pm 13$ & $65 \pm 17$ & 0.158 \\
\hline$D \mathrm{~L}, \mathrm{CO} \mathrm{mL} \cdot \mathrm{min}^{-1} \cdot \mathrm{mmHg}^{-1}$ & $9.77 \pm 3.83$ & $9.67 \pm 3.51$ & 0.861 \\
\hline RV L & $5.02 \pm 1.16$ & $4.98 \pm 1.07$ & 0.814 \\
\hline RV \% pred & $240 \pm 51$ & $240 \pm 47$ & 0.948 \\
\hline TLC L & $7.82 \pm 1.47$ & $7.94 \pm 1.18$ & 0.597 \\
\hline TLC \% pred & $127 \pm 15$ & $129 \pm 14$ & 0.117 \\
\hline \multicolumn{4}{|l|}{ Exercise performance, quality of life } \\
\hline Cycle ergometry peak workload W & $46.9 \pm 20.3$ & $52.2 \pm 23.4$ & 0.117 \\
\hline $6 \mathrm{MWD} \mathrm{m}$ & $341 \pm 108$ & $360 \pm 117$ & 0.396 \\
\hline SGRQ & $59 \pm 13$ & $56 \pm 18$ & 0.150 \\
\hline
\end{tabular}

Data are presented as mean \pm SD or $n(\%)$, unless otherwise stated. EBV: endobronchial valve; $\mathrm{BMI}$ : body mass index; $\mathrm{Pa}_{\mathrm{a}} \mathrm{O}_{2}$ : arterial oxygen tension; $\mathrm{Pa}_{1} \mathrm{CO}_{2}$ : arterial carbon dioxide tension; $\mathrm{FEV}_{1}$ : forced expiratory volume in $1 \mathrm{~s} ; \%$ pred: \% predicted; FVC: forced vital capacity; DL,CO: diffusing capacity of the lung for carbon monoxide; RV: residual volume; TLC: total lung capacity; 6MWD: 6-min walk distance; SGRQ: St George's Respiratory Questionnaire. \#: race was self-reported; $\because$ : measurements were performed while the patient was breathing ambient air. compared with the control group at 6 months, assuming an alpha level of $0.05[21,25]$.

The European arm of the VENT study was initiated due to early concerns over slow patient enrolment in the USA. Ultimately, the rate of patient accrual in the USA exceeded expectations and the sample size as determined $a$ priori was attained by the USA arm of the study. The initial publication of the VENT study data [21] included only the USA arm since its size was sufficient to support the a priori power calculation. The size of the European arm of the VENT study was smaller than the a priori estimate. Nevertheless, evaluation of this data set is important since the European study sample, not included in the initial publication, provides an opportunity to use an independent data set to evaluate key factors observed in the USA study cohort as important considerations for EBV therapy.

Between-group statistical comparisons for the treatment versus control groups were made using the two-sided Fisher's exact test for proportions and two-sided unpaired t-tests for continuous variables.

The USA VENT study indicated that CT assessment suggestive of complete fissure between the target treatment and adjacent lobes, and emphysema heterogeneity were independently associated with higher treatment effect after EBV therapy [21]. In this study, the effect of CT assessment of fissure integrity on clinical outcomes was evaluated by stratifying patients into four groups: 1) EBV with complete fissure, 2) control with complete fissure, 3) EBV with incomplete fissure, and 4) control with incomplete fissure; and evaluating outcomes in all four groups. The effect of lobar occlusion with EBV placement was determined by evaluating clinical outcomes in patients having CT suggestive of complete fissure, where EBV-treated patients were stratified by CT findings for lobar occlusion (present or absent). Between-group statistical comparisons for the post hoc analyses of fissure integrity and lobar occlusion were made using the two-sided Chi-squared or Fisher's exact test for proportions and two-sided t-tests for continuous variables. Statistical comparisons were made using SAS (version 9.3; SAS Institute Inc., Cary, NC, USA). Outcomes for control patients having CT suggestive of complete fissure were included for reference. The effect of emphysema heterogeneity was qualitatively examined by plotting outcomes using descriptive statistics (median and range) for EBV-treated patients having CT suggestive of complete fissure and either $\leqslant 15 \%$ or $>15 \%$ emphysema heterogeneity before treatment.

\section{RESULTS}

\section{Patients and procedural details}

Demographic variables, lung function parameters, blood gases and exercise performance measures were comparable between the treatment and control groups (table 1). The number of patients on oxygen therapy differed significantly between the groups, where a significantly higher number of EBV patients $(72 \%)$ required oxygen therapy compared with control patients $(48 \%$; $=0.002)$. A total of $157(92 \%)$ patients completed the study (fig. 1). During the 1-yr follow-up, 10 patients died, four $(7 \%)$ in the control group and six $(5 \%)$ in the EBV group. None of the deaths was related to the study procedure, as adjudicated by the independent clinical events (safety) committee. 


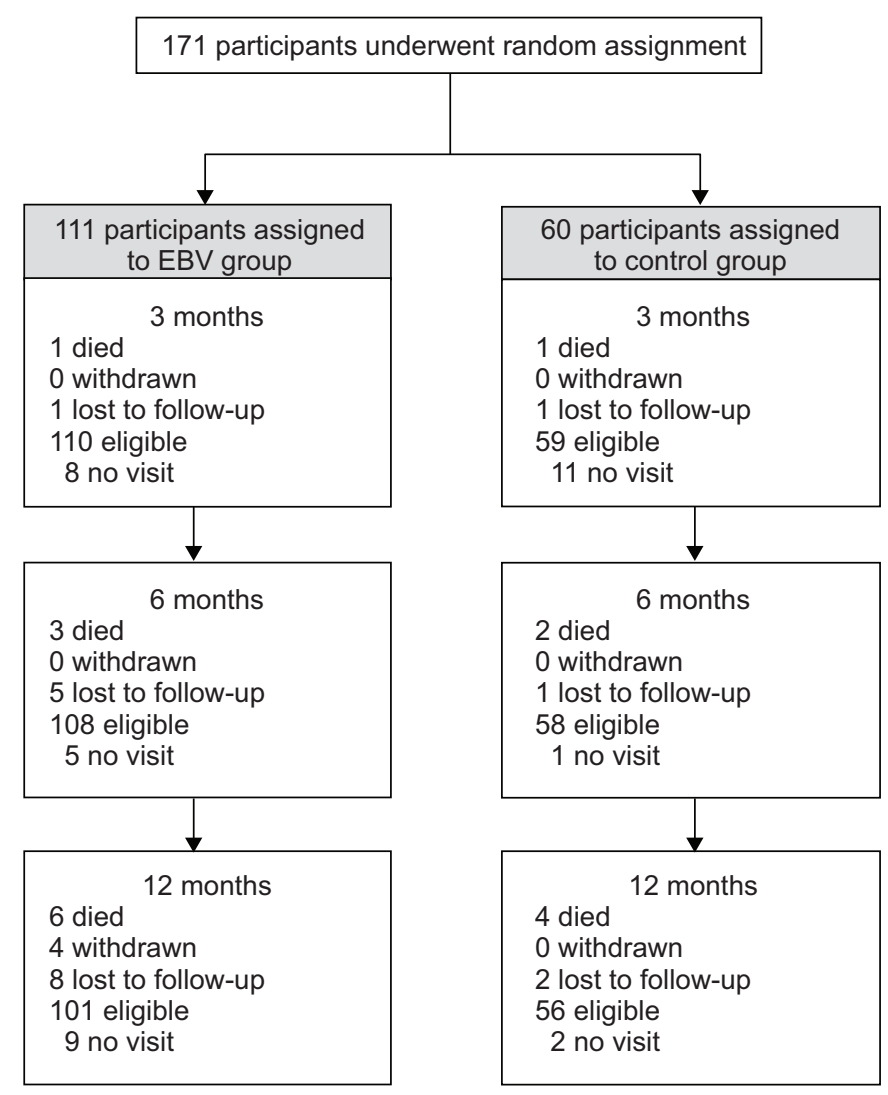

FIGURE 1. Accountability of participants in the European Endobronchial Valve for Emphysema Palliation Trial (VENT study) showed loss to follow-up as expected for an emphysema cohort. EBV: endobronchial valve.

Most valves were placed with the patient under general anaesthesia $(89.1 \%)$ but $12(10.9 \%)$ cases received only moderate sedation. Half of the procedures (50.5\%) were performed using a combination of flexible and rigid bronchoscopy while the other half $(49.5 \%)$ had flexible bronchoscopy alone. Patients received between one and five valves (mean 3 ). The procedure time for valve placement ranged from $16 \mathrm{~min}$ to $105 \mathrm{~min}$ (mean \pm SD $27 \pm 18 \mathrm{~min}$ ). The right upper lobe was most frequently targeted for treatment $(46 \%)$, followed by the left upper lobe, including the lingula (27\%), the right lower lobe $(14 \%)$, and the left lower lobe (13\%). Because the study protocol explicitly specified that patients were to receive unilateral treatment of a single upper or single lower lobe only, the right middle lobe was not considered as a target treatment lobe in this study. In $9 \%$ of cases, valves were not successfully placed as planned because of complex local anatomy.

\section{Outcome variables}

\section{EBV group versus control group}

At 6 months, the EBV patients demonstrated significant or borderline significant $(\mathrm{p} \leqslant 0.05)$ improvement (mean $\pm \mathrm{SD})$ compared with the controls for FEV1 absolute percentage change $(7 \pm 20 \%$ versus $0.5 \pm 19 \%$; $\mathrm{p}=0.067)$, cycle ergometry workload change $(2 \pm 14 \mathrm{~W}$ versus $-3 \pm 10 \mathrm{~W} ; \mathrm{p}=0.04)$ and change in SGRQ score $(-5 \pm 14$ points versus $0.3 \pm 13$ points; $p=0.047)$. The average distance change from baseline for the $6 \mathrm{MWD}$ test was comparable for both groups $(15 \pm 91 \mathrm{~m}$ versus

\begin{tabular}{|c|c|c|c|c|c|c|}
\hline \multirow[t]{3}{*}{ TABLE 2} & \multicolumn{6}{|c|}{$\begin{array}{l}\text { Clinical outcomes at } 6 \text { and } 12 \text { months in } \\
\text { endobronchial valve (EBV)-treated and control } \\
\text { oatients stratified by computed tomography } \\
\text { issure integrity }\end{array}$} \\
\hline & \multicolumn{3}{|c|}{ Complete fissure } & \multicolumn{3}{|c|}{ Incomplete fissure } \\
\hline & EBV & Control" & $\mathrm{p}$-value & EBV & Control & $p$-value \\
\hline $\begin{array}{l}\text { Patients n } \\
\Delta \text { FEV }_{1} \%\end{array}$ & 44 & 19 & & 67 & 40 & \\
\hline 6 months & $16 \pm 21$ & $2 \pm 14$ & 0.02 & $1 \pm 18$ & $-1 \pm 21$ & 0.7 \\
\hline 12 months & $15 \pm 29$ & $-2 \pm 22$ & 0.04 & $0 \pm 23$ & $-2 \pm 19$ & 0.6 \\
\hline$\triangle 6 M W D \%$ & & & & & & \\
\hline 6 months & $11 \pm 34$ & $19 \pm 54$ & 0.6 & $7 \pm 36$ & $2 \pm 19$ & 0.4 \\
\hline 12 months & $13 \pm 35$ & $10 \pm 44$ & 0.8 & $5 \pm 30$ & $0 \pm 34$ & 0.5 \\
\hline $\begin{array}{l}\Delta \text { cycle work- } \\
\text { load W }\end{array}$ & & & & & & \\
\hline 6 months & $4 \pm 14$ & $-3 \pm 7$ & 0.03 & $0 \pm 14$ & $-3 \pm 11$ & 0.4 \\
\hline 12 months & $4 \pm 14$ & $-2 \pm 9$ & 0.10 & $-2 \pm 13$ & $-6 \pm 13$ & 0.2 \\
\hline$\Delta$ SGRQ points & & & & & & \\
\hline 6 months & $-6 \pm 15$ & $3 \pm 15$ & 0.09 & $-4 \pm 14$ & $-1 \pm 14$ & 0.2 \\
\hline 12 months & $0 \pm 15$ & $4 \pm 11$ & 0.4 & $-1 \pm 14$ & $-1 \pm 14$ & 0.9 \\
\hline Lost to follow-up & $7(16)$ & 0 & & $6(9)$ & $2(5)$ & \\
\hline Died & $2(5)$ & 1 (5) & & $4(6)$ & $3(8)$ & \\
\hline
\end{tabular}

Data are presented as mean \pm SD or $n(\%)$, unless otherwise stated. $\Delta$ : change; FEV1: forced expiratory volume in $1 \mathrm{~s}$; 6MWD: 6-min walk distance; SGRQ: St George's Respiratory Questionnaire. ${ }^{*}: \mathrm{n}=1$ control missing fissure integrity data.

$10 \pm 78 \mathrm{~m} ; \mathrm{p}=0.696)$. At 12 months, EBV treatment patients had significantly improved FEV1 $(6 \pm 26 \%$ versus $-2 \pm 20 \% ; \mathrm{p}=0.0499)$ and cycle ergometry workload $(1 \pm 13 \mathrm{~W}$ versus $-5 \pm 12 \mathrm{~W}$; $\mathrm{p}=0.03$ ) scores compared with controls.

\section{Effect of fissure integrity}

A little over one-third of patients $(n=63)$ were found to have had CT suggestive of complete fissure while the other twothirds $(n=107)$ had CT suggestive of incomplete fissure. The EBV patients with CT suggestive of complete fissure tended to have higher improvements in FEV1, SGRQ and cycle ergometry workload than the other subgroups at 6 and 12 months (table 2). In these patients, EBV therapy was associated with significant $(p \leqslant 0.05)$ or borderline significant $(p \leqslant 0.10)$ improvement for FEV1, cycle ergometry workload and SGRQ score. Median (interquartile range) TLVR in EBV patients with CT suggestive of complete fissure was $-55(-24--96) \%$ compared with $-13(-3--22) \%$ for the incomplete fissure EBV subgroup. Neither of the control subgroups (having CT suggestive of complete or incomplete fissure, respectively), demonstrated TLVR $(-1(-4-3) \%$ and $1(-1-5) \%)$.

\section{Effect of complete fissure and lobar occlusion}

CT evidence of lobar occlusion was found in less than half (53 out of $111 ; 48 \%$ ) of the EBV-treated patients. Incomplete lobar occlusion would mean that air could still enter the lobe on inspiration via a partially occluded airway(s). Within the patients with CT suggestive of complete fissure, the EBV patients 


\begin{tabular}{|c|c|c|c|c|}
\hline \multirow{2}{*}{ TABLE 3} & \multicolumn{4}{|c|}{ Complete fissure } \\
\hline & Lobar occlusion & No lobar occlusion & p-value $\#$ & Controls \\
\hline Patients $\mathrm{n}^{\pi}$ & 20 & 17 & & 19 \\
\hline$\geqslant 55 \%$ reduction ${ }^{\S}$ & $15(79)$ & $3(18)$ & 0.0002 & $0(0)$ \\
\hline \multicolumn{5}{|l|}{$\Delta$ TLC L } \\
\hline 6 months & $-0.5 \pm 0.7$ & $-0.4 \pm 1.0$ & 0.7 & $-0.2 \pm 0.5$ \\
\hline 12 months & $-0.3 \pm 0.7$ & $-0.2 \pm 1.2$ & 0.6 & $-0.4 \pm 0.7$ \\
\hline \multicolumn{5}{|l|}{$\Delta$ FEV1 \% } \\
\hline 6 months & $8 \pm 15$ & $0 \pm 14$ & 0.10 & $-3 \pm 7$ \\
\hline 12 months & $6 \pm 16$ & $5 \pm 10$ & 0.9 & $-2 \pm 9$ \\
\hline$\geqslant 10 \mathrm{~W}$ improved & $8(44)$ & $3(27)$ & 0.4 & $1(7)$ \\
\hline \multicolumn{5}{|l|}{$\Delta 6 \mathrm{MWD} \%$} \\
\hline 6 months & $22 \pm 38$ & $-2 \pm 19$ & 0.03 & $19 \pm 54$ \\
\hline 12 months & $22 \pm 40$ & $0 \pm 20$ & 0.06 & $10 \pm 44$ \\
\hline$\geqslant 35 \mathrm{~m}$ improved & $10(56)$ & $3(25)$ & 0.1 & $6(38)$ \\
\hline \multicolumn{5}{|l|}{$\Delta$ SGRQ points } \\
\hline 6 months & $-10 \pm 15$ & $-2 \pm 14$ & 0.2 & $3 \pm 15$ \\
\hline 12 months & $-4 \pm 16$ & $2 \pm 16$ & 0.4 & $4 \pm 11$ \\
\hline$\geqslant 4$ pts improved & $8(67)$ & $4(40)$ & 0.4 & $2(17)$ \\
\hline
\end{tabular}

Data are presented as mean \pm SD or $n(\%)$, unless otherwise stated. $\Delta$ : change; TLVR: target lobe volume reduction; TLC: total lung capacity; FEV1: forced expiratory volume in 1 s; 6MWD: 6-min walk distance; SGRQ: St George's Respiratory Questionnaire; RV: residual volume. "*: t-test comparison of the EBV-treated subgroup having lobar occlusion and the EBV-treated subgroup not having lobar occlusion (the control subgroup having CT suggestive of complete fissure is shown for reference); ": lobar occlusion determination was not available for seven patients; ${ }^{+}$: TLVR based on CT collected at 6 months; ${ }^{\varsigma}: 55 \%$ is presented as the threshold for TLVR since it was the median shown by EBV patients with CT suggestive of complete fissure.

classified as having lobar occlusion demonstrated substantially higher lobar volume reduction compared with both the EBV patients classified as not having lobar occlusion and the controls (table 3). In EBV-treated patients classified as having lobar occlusion, clinical outcomes at both 6 and 12 months were better than outcomes for EBV-treated patients who were classified as not having lobar occlusion and those for controls. At 12 months, minimal clinically important difference thresholds for FEV1, cycle ergometry workload, 6MWD test and SGRQ were met by $67 \%$ (12 out of 18 ), $44 \%$ (8 out of 18$), 56 \%$ (10 out of 18 ) and $67 \%$ (8 out of 12) of this patient subgroup.

\section{Effect of complete fissure, lobar occlusion and distribution of emphysema}

In this analysis, $20 \mathrm{EBV}$ patients had CT assessment suggestive of complete fissure and lobar occlusion: 11 had emphysema heterogeneity scores $>15 \%$ while the other nine patients had scores $\leqslant 15 \%$. Clinically significant improvements were observed in patients with emphysema heterogeneity scores $<15 \%$, which were sustained through 12 months (fig. 2).

\section{Adverse events}

The rates for serious complications did not differ significantly between EBV and control patients (table 4). Occurrence of COPD exacerbations did not differ significantly between the EBV and control groups. The EBV patients demonstrated relatively higher rates for pneumothorax compared with the group where there was no bronchoscopic intervention. Pneumothorax is a known effect of thoracic procedures. In the five EBV cases of pneumothorax requiring hospitalisation for longer than 7 days, high TLVR and a positive clinical response was confirmed in four cases $(91 \%, 93 \%, 93 \%$, and $97 \%)$; in the last case, the CT scan was not collected and therefore TLVR was not known. There was a low incidence of pneumonia 

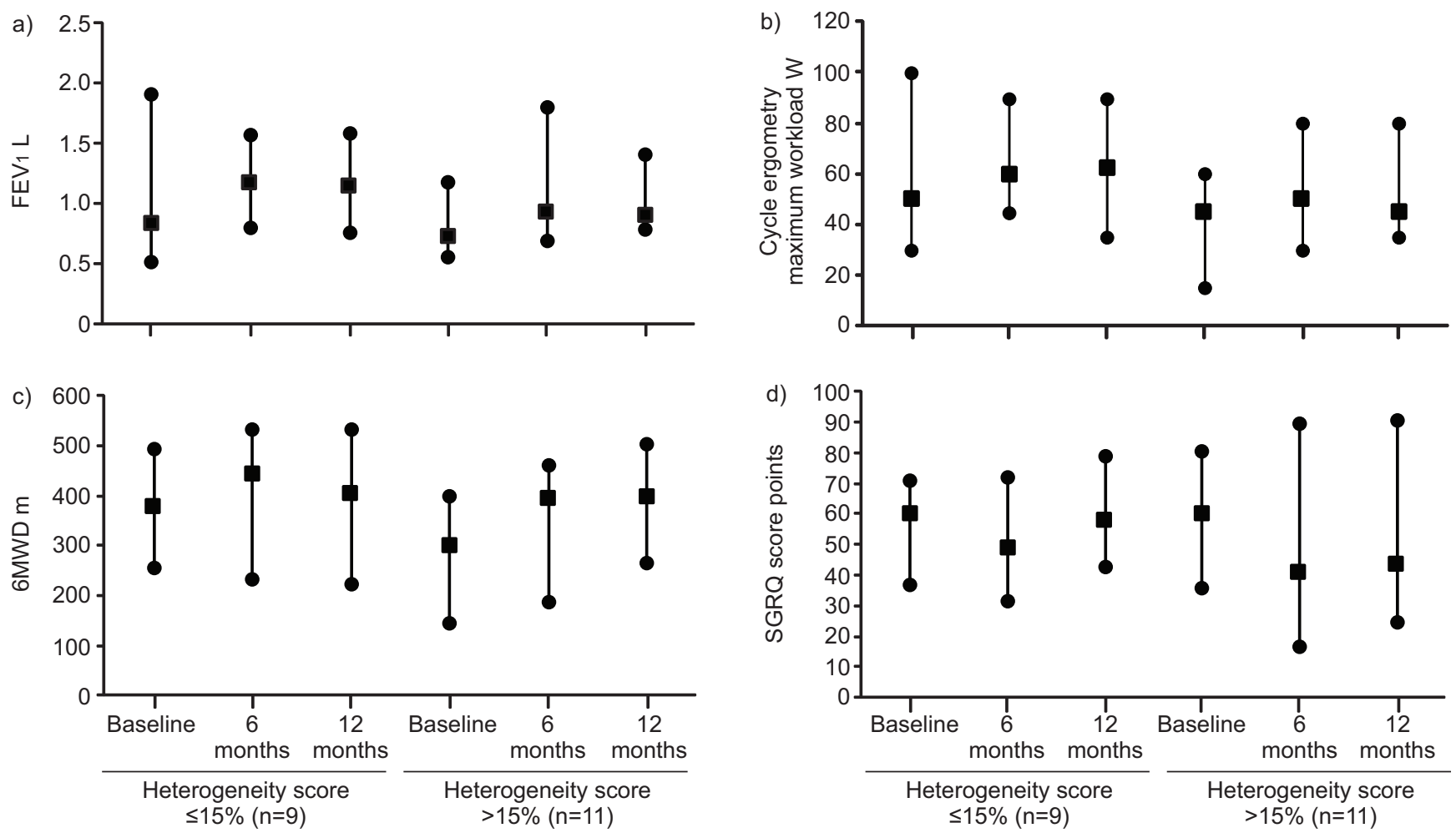

FIGURE 2. a) Forced expiratory volume in $1 \mathrm{~s}$ (FEV1), b) cycle ergometry maximum workload, c) 6-min walk distance (6MWD) test and d) St George's Respiratory Questionnaire (SGRQ) scores (median bounded by minimum and maximum values) at baseline and 6 and 12 months for endobronchial valve (EBV) patients having computed tomography scans suggestive of complete fissure and lobar occlusion. The EBV patients with emphysema heterogeneity scores $\leqslant 15 \%$ responded well through 12 months' follow-up compared with EBV patients with heterogeneity scores $>15 \%$. One patient in each subgroup was lost to follow-up at 6 and 12 months.

distal to the valve in patients receiving EBV therapy. For EBVtreated patients with evidence of pneumonia in the non-treated lobe, approximately half of the pneumonias originated in the ipsilateral lobe and half originated in the opposite lung. No cases of empyema or massive haemoptysis were observed.

\section{EBV-related events}

Over the 12-month follow-up, the rates for valve expectoration, aspiration or migration were $7.2 \%$ (eight out of 111) at $\leqslant 90$ days, $0.90 \%$ (one out of 111) between 98 and 194 days, $3.60 \%$ (four out of 111) between 195 and 284 days and $0.90 \%$ (one out of 111) between 285 and 386 days.

\section{DISCUSSION}

The results of this study showed that greater lobar volume reduction with EBV therapy was found in those patients who had CT suggestive of complete fissure and lobar occlusion. These patients had much greater improvements in FEV1, exercise tolerance and quality of life than either the EBV patients without these conditions or control patients. The group of patients having successful outcomes with EBV therapy included patients with lower emphysema heterogeneity. Furthermore, the subgroup of patients who were observed to have a good clinical response to EBV therapy at 6 months were also likely to demonstrate sustained results at 12 months.

Post hoc analyses of the results of both the USA and European cohorts participating in the VENT study demonstrated the strong influence that anatomical factors, such as collateral ventilation, and technical factors, such as lobar occlusion, have on outcomes with EBV therapy. Both of these factors are strongly associated with lobar volume reduction elicited by EBV treatment. In the analysis of the European cohort, we found that the EBV-treated patients having CT suggesting complete fissure and lobar occlusion had significantly reduced volume reduction in the treated lobe, along with significantly improved clinical outcomes, compared with patients who did not have CT suggestive of complete fissure and lobar occlusion. Our results confirmed the finding from the USA VENT study cohort [21] that presence of complete fissure was associated with enhanced clinical results with EBV treatment. Notably, it has recently been reported that 5-yr survival rates in EBV-treated patients having HRCT evidence of visible fissures exceeded $80 \%$ [27].

In the USA VENT study, it was reported that the mean response to EBV treatment was significantly increased in patients having higher emphysema heterogeneity over patients with lower emphysema heterogeneity [21]. For the analysis of the European study cohort, we investigated clinical outcomes in patients stratified by fissure integrity, lobar occlusion and level of emphysema heterogeneity. In the European cohort, some patients who demonstrated CT suggestive of complete fissure and lobar occlusion with EBV treatment also had lower emphysema heterogeneity scores. We found that these patients benefited from EBV therapy. Post-procedure FEV1 and cycle ergometry scores in this subset of patients were improved and the subgroup median scores exceeded the scores shown by 


\begin{tabular}{|c|c|c|c|c|c|c|c|c|c|c|c|c|}
\hline Event & $\begin{array}{c}\text { EBV } \\
\text { therapy }\end{array}$ & Control & p-value & $\begin{array}{c}\text { EBV } \\
\text { therapy }\end{array}$ & Control & $p$-value & $\begin{array}{c}\text { EBV } \\
\text { therapy }\end{array}$ & Control & $\mathrm{p}$-value & $\begin{array}{c}\text { EBV } \\
\text { therapy }\end{array}$ & Control & p-value \\
\hline Death & $1(0.9)$ & $1(1.7)$ & 1.00 & $2(1.8)$ & 0 & 0.54 & $2(1.8)$ & 0 & 0.54 & $1(0.9)$ & $3(5.0)$ & 0.12 \\
\hline Respiratory failure & $4(3.6)$ & $1(1.7)$ & 0.66 & $3(2.7)$ & $3(5.0)$ & 0.42 & $3(2.7)$ & $1(1.7)$ & 1.00 & 0 & $1(1.7)$ & 0.35 \\
\hline$\geqslant 24 \mathrm{~h}$ ventilation & $2(1.8)$ & 0 & 0.54 & $2(1.8)$ & $1(1.7)$ & 1.00 & $3(2.7)$ & 0 & 0.55 & 0 & $1(1.7)$ & 0.35 \\
\hline Haemoptysis & $6(5.4)$ & $1(1.7)$ & 0.42 & $4(3.6)$ & 0 & 0.30 & $1(0.9)$ & 0 & 1.00 & $3(2.7)$ & 0 & 0.55 \\
\hline Massive & 0 & 0 & & $1(0.9)$ & 0 & 1.00 & 0 & 0 & & 0 & 0 & \\
\hline Pneumothorax or air leak & $5(4.5)$ & 0 & 0.16 & $1(0.9)$ & 0 & 1.00 & $1(0.9)$ & 0 & 1.00 & $2(1.8)$ & 0 & 0.54 \\
\hline COPD exacerbation & $47(42.3)$ & $28(46.7)$ & 0.63 & $36(32.4)$ & $19(31.7)$ & 1.00 & $16(14.4)$ & $9(15.0)$ & 1.00 & $17(15.3)$ & $12(20.0)$ & 0.52 \\
\hline With hospitalisation & $13(11.7)$ & $6(10.0)$ & 0.80 & $13(11.7)$ & $7(11.7)$ & 1.00 & $12(10.8)$ & $3(5.0)$ & 0.26 & $4(3.6)$ & $2(3.3)$ & 1.00 \\
\hline Without hospitalisation & 31 (27.9) & $23(38.3)$ & 0.17 & $21(18.9)$ & $13(21.7)$ & 0.69 & $6(5.4)$ & $6(10.0)$ & 0.35 & $13(11.7)$ & $10(16.7)$ & 0.36 \\
\hline
\end{tabular}

Data are presented as n (\%), unless otherwise stated. COPD: chronic obstructive pulmonary disease.

patients with more heterogeneous emphysema. In the USA study cohort, patients with lower emphysema heterogeneity scores were found, on average, to have a mediated response to EBV treatment. However, results for individual patients were not reported. The results of the European study group suggest that in patients having evidence of complete fissure and lobar occlusion with EBV treatment, level of emphysema heterogeneity did not preclude achieving TLVR and having excellent clinical outcomes.

The safety profile of the EBV procedure reported in the USA cohort of patients was further validated by this study. Although morbidity related to the procedure was observed, it was generally minor and managed medically using conventional therapies, such as antibiotic treatment. The EBV group demonstrated a rate of approximately $5 \%$ for pneumothorax early after the procedure; this is an expected event following a thoracic procedure. In the patients who had a pneumothorax associated with lobar volume reduction, all had substantial lobar volume changes seen on HRCT, along with excellent clinical outcomes in most cases. Of note, COPD exacerbations did not differ significantly between the EBV and control groups. In fact, the rates for both groups were almost identical at 3, 6, 9 and 12 months.

High lobar volume reduction with EBV therapy was associated with CT suggestive of complete fissure between the treated and adjacent lobes, an observation which suggests a lack of collateral ventilation between lobes $[19,20]$ and complete lobar occlusion. The identification of the criteria enabling successful treatment of emphysema patients should allow clinicians to eliminate some restrictions on patient selection, such as low heterogeneity. A catheter-based system is showing promise in the assessment of collateral ventilation. In a feasibility study, collateral ventilation was quantified using the catheter system to predict atelectasis after EBV placement [20].
In the VENT study, CT scans collected at 6 months were evaluated for evidence that valve placement resulted in lobar occlusion. We observed that lobar occlusion was an important adjunct to complete fissure for achieving good clinical response with EBV therapy. In the EBV-treated patients, those who were classified by the core reading laboratory as showing evidence of well-seated valves in the airways of the treated segment had significantly improved clinical outcomes over patients who demonstrated radiological evidence of air flow between the valve and airway wall. Since the VENT study was completed, technical improvements have been made to the EBV delivery system, most notably introduction of a depth marker on the deployment catheter, which are designed to facilitate accurate valve placement. The depth marker ensures full seating of the EBV device within the target lumen and minimises the risk of incomplete lobar occlusion or potential migration.

This study had two limitations. The size of the European study cohort lacked the power to support drawing discrete conclusions in regard to the a priori clinical investigation plan. However, the findings support those of the USA VENT study [21]. The EBV treatment was associated with significantly improved clinical outcomes over medical management, although the difference, in some cases, was of borderline statistical significance. Additionally, CT suggestive of fissure integrity and lobar occlusion were important correlates of clinical response. One potential disadvantage of the VENT study design was the choice of control group. A sham procedure was not performed as the control, as this was not deemed an appropriate comparator at the time the study was planned. Sham procedures may be important, particularly when clinical assessments include quality of life measures. Nevertheless, the principal clinical measures in this study included objective parameters, such as volume reduction as determined using blinded assessment of CT scans, pulmonary function, and exercise 
performance, which are all less likely to be influenced by a placebo effect.

Unilateral lobar occlusion with EBV therapy proved effective in achieving TLVR and improving lung mechanics, exercise performance, and health-related quality of life measures in European patients with emphysema. Patients having CT suggestive of complete fissure and lobar occlusion with the EBV demonstrated significantly improved clinical results with EBV therapy. Results of EBV therapy in emphysema patients are optimised when the target treatment lobe shows no evidence of collateral ventilation and where valves are placed to achieve lobar occlusion. This data suggests that the most important factors determining success are related to anatomical factors (collateral ventilation) and technical factors (complete lobar occlusion). Further study should be conducted to determine whether broader groups of emphysema patients can achieve the significant clinical benefits demonstrated by this subgroup of patients. This study showed that EBV therapy was used to achieve good results when a lobe having no evidence of collateral ventilation is completely occluded with EBVs.

\section{SUPPORT STATEMENT}

The study was sponsored by Emphasys Medical (now Pulmonx, Inc). All authors were investigators in the study and had full access to the data. None of the investigators or authors had any financial relationships during the trial with the study sponsor (Emphasys Medical).

\section{CLINICAL TRIAL}

This study is registered at www.clinicaltrials.gov with identifier number NCT00129584.

\section{STATEMENT OF INTEREST}

Statements of interest for F.J.F. Herth, J-M. Vergnon, J.H. Ficker, D. Holmes-Higgin and A. Ernst, and for the study itself can be found at www.erj.ersjournals.com/site/misc/statements.xhtml

\section{ACKNOWLEDGEMENTS}

F.J.F. Herth: Hospital Thoraxklinik, University of Heidelberg, Member of the German Center for Lung Research, Heidelberg, Germany. M. Noppen: University Hospital Brussels, Brussels, Belgium. A. Valipour: Ludwig-Boltzmann-Institute for COPD and Respiratory Epidemiology, Otto Wagner Spital, Vienna, Austria. S. Leroy: Hôpital Calmette, Centre Hospitalier Régional Universitaire de Lille, Lille, France. J-M. Vergnon: Service de Pneumologie et d'Oncologie Thoracique, Centre Hospitalier Universitaire de Saint Etienne - Hôpital Nord, Saint Etienne, France. J.H. Ficker: Schwerpunkt Pneumologie, Klinikum Nürnberg/Klinikum Nord, Nuremberg, Germany. J.J. Egan: Advanced Lung Disease and Lung Transplant Program, Mater Misericordiae University Hospital, Dublin, Ireland. S. Gasparini: Pneumology, Azienda Ospedaliero Universitaria Ospedali Riuniti di Ancona, Ancona, Italy. C. Agusti: Institut Cínic de Pneumologie i Ciruria Toràcica, Hospital Cínic de Barcelona, Barcelona, Spain. D. Holmes-Higgin: Clinical Research Dept, Pulmonx Inc., Redwood City, CA, USA. A. Ernst: Interventional Pulmonology, St Elizabeth's Medical Center, Boston, MA, USA.

The authors would like to thank the study International VENT study investigators and clinical sites for their diligent efforts in recruiting and following up the patients participating in this study. The International VENT study investigators and their clinical sites are as follows: C. Marquette, S. Leroy, and T. Perez (Hôpital Calmette, Centre Hospitalier Régional Universitaire de Lille, Lille, France); M. Noppen and M. Meysman (University Hospital Brussels, Brussels, Belgium); P. Germonpré and W. DeBacker (University Hospital Antwerp, Edegem, Belgium); O.C. Burghuber and A. Valipour (Dept of Respiratory and
Critical Care Medicine, Otto Wagner Hospital, Vienna, Austria); W. Klepetko and A. End (Dept of Cardiothoracic Surgery, University Clinic Vienna, Vienna, Austria); J.J. Egan (Mater Misericordiae Hospital, Dublin, Ireland); T. Similowski (Service de Pneumologie, Groupe Hospitalier Pitié Salpétrière, Paris, France); E. Hecker (Chefarzt Klinik für Thoraxchirurgie, Klinikum Bremen-Ost gGmbH, Bremen, Germany); H. Mal (Groupe Hospitalier Bichât - Claude Bernard Service de Pneumologie, Hôpital Beaujon, Paris, France); P. Thomas and H. Dutau (Service de Chirurie Thoracique, Hôpital Sainte Marguerite, Marseille, France); J.H. Ficker and R. Leistner (Schwerpunkt Pneumologie, Klinikum Nürnberg/Klinikum Nord, Nuremberg, Germany); F.J.F. Herth (Hospital Thoraxklinik, University of Heidelberg, Member of the German Center for Lung Research, Heidelberg, Germany); F. Lebargy (Service de Pneumologie, Centre Hospitalier Universitaire de Reims, Reims, France); F. Stanzel, N. Weber and M. Menzel (Klinik für Pneumologie, Asklepios Fachkliniken München-Gauting, Gauting, Germany); A. Torres, C. Agusti and M. Melgosa (Institut Clínic de Pneumologie i Ciruria Toràcica, Hospital Clínic de Barcelona, Barcelona, Spain); A. Agusti (Servei Respiratori, Hospital Universitari Son Dureta, Palma Mallorca, Spain); M. Dahan (Service de Chirurie Thoracique, Centre Hospitalier Universitaire de Toulouse, Hôpital Larrey, Toulouse, France); G. Massard and R. Kessler (Service de Chirurgie Thoracique, Centre Hospitalier Universitaire de Strasbourg, Hôpital Civil, Strasbourg, France); C. Pison (RCH, DMAS, Centre Hospitalier Universitaire de Grenoble, Grenoble, France); J-M. Muir (Service de Pneumologie, Centre Hospitalier Universitaire de Rouen, Rouen, France); M. Febvre (Service de Pneumologie, Hôpital Saint-Antoine, Paris, France); C. Witt (Schwerpunkt Pneumologie, Charité Campus Mitte, Berlin, Germany); J-M. Vergnon (Service de Pneumologie et d'Oncologie Thoracique, Centre Hospitalier Universitaire de Saint Etienne - Hôpital Nord, Saint Etienne, France); S. Gasparini (Direttore U.O. Pneumologia, Azienda Ospedaliera "Umberto I", Ancona, Italy).

The authors would also like to thank J. Goldin and his staff (David Geffen School of Medicine at UCLA, Los Angeles, CA, USA) for their contribution to the study as the core radiology laboratory, and T. Crabtree, a biostatistics consultant, for her contribution related to statistical evaluation of the data.

\section{REFERENCES}

1 Barr RG, Celli BR, Martinez FJ, et al. Physician and patient perceptions in COPD: the COPD Resource Network Needs Assessment Survey. Am J Med 2005; 118: 1415.

2 Mannino DM, Homa DM, Akinbami LJ, et al. Chronic obstructive pulmonary disease surveillance - United States, 1971-2000. MMWR Surveill Summ 2002; 51: 1-16.

3 Criner GJ, Cordova FC, Furukawa S, et al. Prospective randomized trial comparing bilateral lung volume reduction surgery to pulmonary rehabilitation in severe chronic obstructive pulmonary disease. Am J Respir Crit Care Med 1999; 160: 2018-2027.

4 Fishman A, Martinez F, Naunheim K, et al. A randomized trial comparing lung-volume-reduction surgery with medical therapy for severe emphysema. N Engl J Med 2003; 348: 2059-2073.

5 Naunheim KS, Wood DE, Krasna MJ, et al. National Emphysema Treatment Trial Research Group. Predictors of operative mortality and cardiopulmonary morbidity in the National Emphysema Treatment Trial. J Thorac Cardiovasc Surg 2006; 131: 43-53.

6 Naunheim KS. Lung-volume reduction surgery: a vanishing operation? J Thorac Cardiovasc Surg 2007; 133: 1412-1413.

7 Snell GI, Holsworth L, Borrill ZL, et al. The potential for bronchoscopic lung volume reduction using bronchial prostheses: a pilot study. Chest 2003; 124: 1073-1080.

8 Toma TP, Hopkinson NS, Hillier J, et al. Bronchoscopic volume reduction with valve implants in patients with severe emphysema. Lancet 2003; 361: 931-933. 
9 Toma TP, Hopkinson NS, Polkey MI, et al. Endobronchial volume reduction: a myth or a marvel? Semin Respir Crit Care Med 2004; 25: 399-404.

10 Hopkinson NS, Toma TP, Hansell DM, et al. Effect of bronchoscopic lung volume reduction on dynamic hyperinflation and exercise in emphysema. Am J Respir Crit Care Med 2005; 171: 453-460.

11 Venuta F, de Giacomo T, Rendina EA, et al. Bronchoscopic lungvolume reduction with one-way valves in patients with heterogeneous emphysema. Ann Thorac Surg 2005; 79: 411-416.

12 Wan IY, Toma TP, Geddes DM, et al. Bronchoscopic lung volume reduction for end-stage emphysema: report on the first 98 patients. Chest 2006; 129: 518-526.

13 Reilly J, Washko G, Pinto-Plata V, et al. Biological lung volume reduction: a new bronchoscopic therapy for advanced emphysema. Chest 2007; 131: 1108-1113.

14 Wood DE, McKenna RJ Jr, Yusen RD, et al. A multicenter trial of an intrabronchial valve for treatment of severe emphysema. J Thorac Cardiovasc Surg 2007; 133: 65-73.

15 Choong CK, Macklem PT, Pierce JA, et al. Airway bypass improves the mechanical properties of explanted emphysematous lungs. Am J Respir Crit Care Med 2008; 178: 902-905.

16 Fessler HE, Scharf SM, Ingenito EP, et al. Physiologic basis for improved pulmonary function after lung volume reduction. Proc Am Thorac Soc 2008; 5: 416-420.

17 D'Andrilli A, Vismara L, Rolla M, et al. Computed tomography with volume rendering for the evaluation of parenchymal hyperinflation after bronchoscopic lung volume reduction. Eur J Cardiothoracic Surg 2009; 35: 403-407.

18 Travaline JM, McKenna RJ, De Giacomo T, et al. Treatment of persistent pulmonary air leaks using endobronchial valves. Chest 2009; 136: 355-360.
19 Conforti S, Torre M, Fieschi S, et al. Successful treatment of persistent post-operative air leaks following the placement of an endobronchial one-way valve. Monaldi Arch Chest Dis 2010; 73: 88-91.

20 Gompelmann D, Eberhardt R, Michaud G, et al. Predicting atelectasis by assessment of collateral ventilation prior to endobronchial lung volume reduction: a feasibility study. Respiration 2010; 80: 419-425.

21 Sciurba F, Ernst A, Herth FJ, et al. A randomized study of endobronchical valves for advanced emphysema. N Engl J Med 2010; 363: 1233-1244.

22 Hopkinson NS, Kemp SV, Toma TP, et al. Atelectasis and survival after bronchoscopic lung volume reduction for COPD. Eur Respir J 2011; 37: 1346-1351.

23 Shah PL, Slebos DJ, Cardoso PF, et al. ; Bronchoscopic lung-volume reduction with Exhale airway stents for emphysema (EASE trial): randomised, sham-controlled, multicentre trial. Lancet 2011; 378: 997-1005.

24 Venuta F, Diso D, Anile M, et al. Bronchoscopic lung volume reduction as a bridge to lung transplantation in patients with chronic obstructive pulmonary disease. J Cardio Thoracic Surg 2011; 39: 364-367.

25 Strange C, Herth FJ, Kovitz KL, et al. Design of the Endobronchial Valve for Emphysema Palliation Trial (VENT): a non-surgical method of lung volume reduction. BMC Pulm Med 2007; 7: 10.

26 Global Initiative for Chronic Obstructive Lung Disease. Global Strategy for the Diagnosis, Management and Prevention of Chronic Obstructive Pulmonary Disease. NHLBI/WHO workshop report. NIH Publication No. 2701: 1-100. Bethesda, National Heart, Lung and Blood Institute, April 2001.

27 Venuta F, Anile M, Diso D, et al. Long term follow up after bronchoscopic lung volume reduction in patients with emphysema. Eur Respir J 2012; 39: 1084-1089. 